Proceedings of the International Congress on Advances in Applied Physics and Materials Science, Antalya 2011

\title{
Some Applications of the Image Analysis in the Metal Material Science
}

\author{
Z. Odanović ${ }^{a}$, M. ĐurĐevićc ${ }^{b}$ J. Krstić Pavlovićc ${ }^{c}$ M. Arsić ${ }^{a}$ \\ AND B. KATAVIĆ ${ }^{d}$ \\ ${ }^{a}$ IMS Institute, Bulevar vojvode Mišića 43, 11000 Belgrade, Serbia \\ ${ }^{b}$ Nemak Linz, Zeppelinstr. 24, 4030 Linz, Austria \\ ${ }^{c}$ Otto-von-Guericke, Universität Magdeburg, IFQ, Universitätspl. 2, 39104 Magdeburg, Germany \\ ${ }^{d}$ Institute Goša, Milana Rakića 35, 11000 Belgrade, Serbia
}

\begin{abstract}
In different areas of science such as medicine, biology and engineering the image analysis is widely used. Quantitative measuring by the image analysis has also found application in metal materials science, especially in metallographic microstructure analysis. The measuring of the linear and area dimensions of the microconstituents in the metal material structure performed by the image analysis is presented in the paper. The effects of the heat treatment temperature on the brittle phase content in the structure of the heat resistant $\mathrm{Ni}-\mathrm{Cr}-\mathrm{Co}-\mathrm{W}$ alloy were analysed. Investigation of the influence of the alloying elements content in the $\mathrm{Al}$ alloys for automotive application, on dendrite arm spacing in the cast structure are also presented. Obtained results of the quantitative measured dimensions have shown direct impact of the process parameters on the analysed metals microstructure characteristics. All tests were performed by the light optical microscope with automatic image analyser. Presented experimental results are based on a large number of measurements. A statistical analysis was performed and a high correlation of the results was obtained. For each of the presented investigations and analyzed phenomenon, a statistical mathematical model is suggested with the boundary conditions defined by the investigated intervals of variables.
\end{abstract}

PACS: 81.05.Bx, 81.30.Fb, 81.40.Cd

\section{Introduction}

Image analysis (IA) is widely used in different areas of science such as medicine, biology and engineering. Quantitative measurement by the image analysis has served the automotive, aerospace, metal fabrication, foundry, welding or other related materials design, fabrication or testing industry. IA also found application in metallurgical engineering, especially in analyzing metallographic microstructures. Structure measurements as cast structure properties, failure analysis and welding structures measurement have received considerable attention in recent years, partly because of development of stereological methods and the importance made in image analysis. Quantitative measurement of microstructure is of great importance in quality control studies as well as in structure property control.

Development of automatic image analysis coupled with corresponding software, has greatly increased the use of stereological principles for determining microstructure characteristics. These devices reduce the time necessary for manual measurements, improve accuracy of statistical measurements, reduce time and eliminate the influence of operator estimation to the minimum level. Some different metallurgical problems were analysed in presented investigation, based on the measuring dimensions of the microstructural/macrostructural components by the IA in relation to the process parameters. Measuring of the brittle phase in steel microstructure and dimensions as secondary dendrite arm spacing (SDAS) in a cast $\mathrm{Al}$ alloy were performed. Effects on microstructural and mechanical properties were analysed. All tests were performed by the light optical microscope (LOM) with automatic image analyser.

\section{Experimental}

\subsection{Brittle phase content in the $\mathrm{Ni}-\mathrm{Cr}-\mathrm{Co}-\mathrm{W}$ alloy microstructure}

Determination of the brittle phase content in the microstructure of the heat resistant $\mathrm{Ni}-\mathrm{Cr}-\mathrm{Co}-\mathrm{W}$ alloy ( $\mathrm{Su}-$ pertherm) tube was performed in investigation. Supertherm is a cast nickel-chromium-iron alloy stabilized with cobalt and tungsten. It is used worldwide in extremely high-temperature applications up to $1260^{\circ} \mathrm{C}$. Among its many uses are for example: components for heat-treating furnaces, cement kilns, petrochemical furnace tubes, and refining furnace tubes [1]. A centrifugally cast riser tube from an ammonia plant was exposed for about $70000 \mathrm{~h}$ at operating temperature of $850^{\circ} \mathrm{C}$ and was fractured. For weld repairing of the tube it was necessary for the alloy to be previously prepared. Usual way for obtaining optimal microstructure for repair welding of the investigated alloy is high temperature dissolving of the brittle phases. For defining the optimal temperature for heat treatment a diffusion annealing at temperatures in the $50^{\circ} \mathrm{C}$ interval, from $1150^{\circ} \mathrm{C}$ to $1250^{\circ} \mathrm{C}$ during $1-3 \mathrm{~h}$ was performed and microstructure was analysed for each investigated temperature. 
Samples for investigation were prepared for optical microscopy by classic method of grinding and polishing. Etching was performed in aquaregia. Quantitative metallographic measurements were based on the image analysis. Heat treatment effects on quantity of brittle $(\sigma)$ phase and carbides in the microstructure were analysed. Based on the black/white contrast, the total area of brittle phases and a number of brittle phase areas in analysed microstructure were determined by image analysis. Applied magnification was 200 times on LOM. Ten measurements were performed at each sample, and then the highest and lowest value were rejected and mean value of remaining eight measurements were presented as result.

\subsection{Properties of the cast Al alloys microstructure}

Most important practical aspect of the cast dendrite structure is the SDAS that represents the distance between secondary dendrites in the solidifying structure of cast metals and alloys. In order to investigate the impact of SDAS in $\mathrm{Al}-\mathrm{Si}-\mathrm{Cu}$ alloys on tensile properties of the $\mathrm{AlSi}_{7} \mathrm{Cu}_{3}$ alloy was cast in the permanent metal mould. The mould has been preheated at three different temperatures: 250,300 and $350^{\circ} \mathrm{C}$ with and without water cooling. In that case 6 different solidification rates have been achieved.

The $\mathrm{Al}$ alloy ingots for testing were produced in a $10 \mathrm{~kg}$ electrical resistance furnace with $\mathrm{SiC}$ crucible. The melting temperature was kept at $720^{\circ} \mathrm{C} \pm 5^{\circ} \mathrm{C}$. The liquid metal was then poured into a permanent metal mould in the pre-form of tensile testing samples. These samples then were machined in the final form of tensile testing samples according to specifications of DIN 50 $125-\mathrm{B} 5 \times 25$. Tensile testing was carried out at a strain rate of $2 \mathrm{~mm} / \mathrm{min}$ at room temperature. Three specimens were tested for each experimental condition and mean values of both yield and ultimate tensile strengths have been determined. After tensile testing, specimens were sectioned parallel to the tensile direction and then prepared using standard metallographic procedure (grinding and polishing). Because the dendrites were clearly visible, no etching was performed. Microstructural changes in the form of the secondary dendrite arm spacing, SDAS values quantified using image analyzer software coupled with LOM were analyzed at the magnification 200 times. The linear intersection method has been used to determine the SDAS.

\section{Results and discussion}

\subsection{Heat treatment effects on the $\mathrm{Ni}-\mathrm{Cr}-\mathrm{Co}-\mathrm{W}$ alloy microstructure}

A lot of trials and errors is involved when it comes to repair welding of service exposed high temperature cast materials and depending on the source a different weld repair strategies are proposed and applied. One of the methods used to enhance weldability is solution annealing before welding. The data from literature showed that embrittlement caused with brittle phases, as secondary carbides and $\sigma$-phase, could be eliminated and original ductility restored by a solution annealing heat treatment [1]. In the present work, the aim was to assess the optimal temperature for solution annealing for preparing alloy for weld repairing.

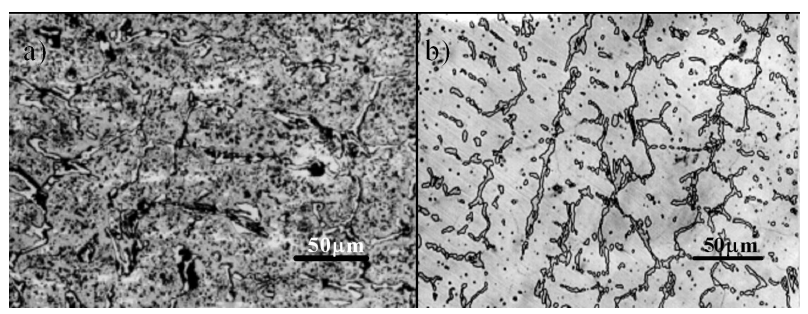

Fig. 1. Microstructure samples of the Supertherm alloy investigated by the IA, (a) without heat treatment, (b) after heat treatment at $1250^{\circ} \mathrm{C} / 1 \mathrm{~h}$, etched in aquaregia.

The microstructure of the samples for investigations is presented in Fig. 1. The sample of the as received microstructure without high temperature heat treatment is shown in Fig. 1a, while sample of the treated microstructure at $1250^{\circ} \mathrm{C}$ for $1 \mathrm{~h}$ is shown in Fig. 1b. The areas and number of the brittle phases at the grain boundaries and inside the grain were measured.

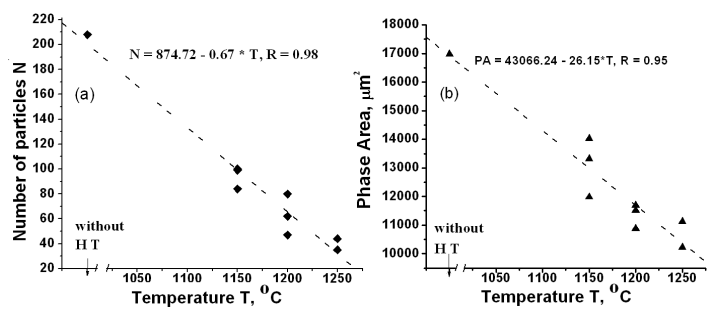

Fig. 2. The effect of heat treatment temperature on the overall quantity of $\sigma$ hase and carbides particles in analyzed microstructures: (a) number of particle, (b) area of particles.

The results of the quantitative metallographic measurements based on the image analysis are presented. The effects of heat treatment temperature on the quantity of brittle phases as $\sigma$-phase and carbides are presented in Fig. 2. It is evident that with the increase of the annealing temperature there is decrease of total area and number of $\sigma$-phase and carbide particles in relation to untreated condition (without high temperature, HT). Such behaviour is result of their dissolution in austenite $\gamma$-phase.

From the result obtained by IA, it is obvious that the temperature of $1250{ }^{\circ} \mathrm{C}$ offers the best effects of brittle phases dissolution and therefore it could be suggested for enhancing weldability and for preparation for repair welding of an investigated material. It has to be noted that this temperature is close to the temperature of liquation of certain Supertherm alloy microconstituents. 
Therefore, annealing temperature between $1150{ }^{\circ} \mathrm{C}$ to $1200^{\circ} \mathrm{C}$ is suggested for heat treatment of investigated alloy.

The results of regression analysis has shown high correlation coefficient $R$ between 0.95 and 0.98 , which indicates that obtained results could be applied for determination of the analysed values in the analysed temperature interval.

\subsection{Secondary dendrite arm spacing in a cast Al alloy}

A comprehensive understanding of melt quality is of paramount importance for the control and prediction of actual casting characteristics. Most important practical aspect of the cast dendrite structure is the SDAS. This quantity is significant because it has been shown that many mechanical properties can be related to it, with the best properties always associated with the smallest SDAS $[2,3]$. A sample of the analysed aluminium-silicon alloy microstructure and schematic representation of dendrites showing measured SDAS are presented in Fig. 3.

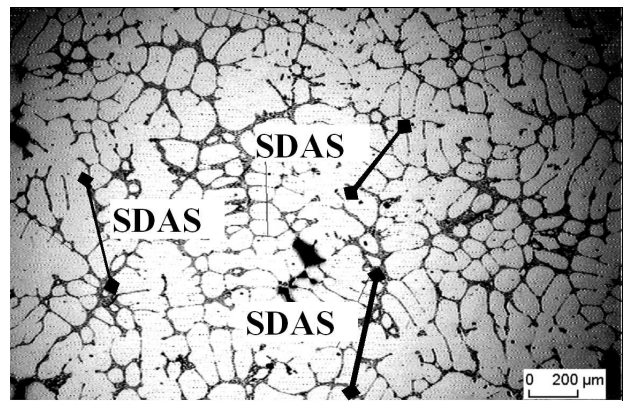

Fig. 3. Sample of the analysed aluminium-silicon alloy microstructure and measured SDAS.

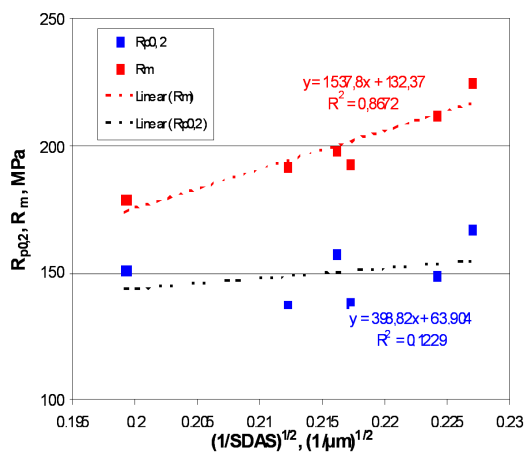

Fig. 4. Yield strength and ultimate tensile strength as a function of $\mathrm{SDAS}$ of $\mathrm{AlSi}_{7} \mathrm{Cu}_{3}$.

The results of tensile tests are summarized in Fig. 4, where the yield strength, $R_{\mathrm{p} 0,2}$ and ultimate tensile strength, $R_{\mathrm{m}}$, are plotted as a function of the reciprocal of the square root of SDAS, $(1 / \mathrm{SDAS})^{1 / 2}$ for six different cooling rates. It can be seen that $R_{\mathrm{m}}$ increases with decreasing SDAS, while $R_{\mathrm{p} 0,2}$ seems to be independent of the dendritic arrangement. The fast cooling of samples solidified in metallic moulds achieves a degree of structural refinement of the silicon particles which can be even comparable with that resulting from modification (depending on section thickness).
The dendrite arm spacing of the Al-rich matrix is also affected, being smaller for higher cooling rates (shorter solidification time). The combination of such structural features influences the tensile properties. The smaller dendritic arm spacing will be associated with a more extensive distribution of the silicon particles in the interdendritic regions and thus contributing to the increase in tensile strength. Coupling results from the present experimental analysis allows establishing experimental equations, as indicated in Fig. 4, expressing the dependence of $R_{\mathrm{m}}$ and $R_{\mathrm{p} 0,2}$ on the secondary dendrite arm spacing.

\section{Conclusions}

Quantitative measurement by the image analysis (IA) applied in metal material engineering is presented. Two different problems were analysed based on the measurement of the dimensions of the microstructural components by the IA in relation to the process parameters.

Determination of the brittle phase content in the function of the heat treatment temperature for the heat resistant $\mathrm{Ni}-\mathrm{Cr}-\mathrm{Co}-\mathrm{W}$ alloy, with the purpose to acquire optimal microstructure for repair welding are presented. Results have shown that the best effect of the brittle phases dissolving is obtained at the heat treatment temperature interval from $1150{ }^{\circ} \mathrm{C}$ to the $1200^{\circ} \mathrm{C}$.

The effects of the microstructural features as SDAS on the tensile properties of an as-cast $\mathrm{Al}$ alloy $\mathrm{AlSi}_{7} \mathrm{Cu}_{3}$ for automotive industry are also presented. The results of investigations show a significant influence of SDAS on the ultimate tensile strength, $R_{\mathrm{m}}$ in as-cast $\mathrm{AlSi}_{7} \mathrm{Cu}_{3}$ alloy. The correlation between $R_{\mathrm{m}}$ and SDAS can be described by the Hall-Petch equation, showing relatively high regression coefficient. It is evident that the yield strength of the as-cast alloy is less sensitive to the SDAS changes.

All presented experimental results are based on a large number of measurements by the IA. High correlation coefficients for the regression equations of the results were obtained for each of the presented investigations.

\section{Acknowledgments}

This work was carried out in a scope of the project TR 35002: "Development of new revitalization methodologies for hydro power plant turbine and hydro-mechanical equipment in relation to causes of material degradation" supported by the Ministry of Science and Technological Development, Republic of Serbia.

\section{References}

[1] A.S.M. Standard, SS-228 SUPERTHERM, www . techstreet.com/standards/ASM/SS_228 .

[2] Z. Odanovic, M.B. Đurđevic, G. Byczynski, B. Katavic, WIT Trans. Eng. Sci. 64, 259 (2009).

[3] J. Pavlović-Krstić, Z. Odanović, V. Grabulov, G. Krstić, R. Bähr, Foundry-Livarstvo 49, 3 (2010). 